\title{
A Systemic Functional Linguistics Analysis of Technical Written Texts Produced by Undergraduate Saudi Engineering Students
}

\author{
Mohammed Al Otaibe \\ College of Arts and Humanities, Taibah University, Saudi Arabia \\ *E-mail: mjotaibi@taibahu.edu.sa
}

\begin{abstract}
Implementing systemic functional linguistics, in particular Theme-Rheme system as a method of teaching writing has been recommended and suggested in many studies The present small-scale paper aimed to analyze 7 texts produced by Saudi engineering students and found that six students faced problems in developing their paragraphs. Results indicate that all the students mainly used unmarked topical Themes. Four students utilized marked topical Themes with differences in terms of the number of uses. Six students used textual Themes in their texts, while three students employed interpersonal Themes in their texts. Moreover, the analysis revealed many problems committed by students. These were: the problem of confusing selection textual Themes, the problem of brand new Theme, the problem of empty Rheme, and the problem of using cohesive devices inappropriately. There was one student could develop his text consistently and cohesively. To sum up, the paper was carried out for shedding light on the problems of Saudi engineering students when writing in English; even though the data was small, bringing the notion of Theme-Rheme into/to the light can be useful for instructors to put the basic principles of Theme-Rheme into practice when teaching writing.
\end{abstract}

Keywords: SFL, technical writing, engineering students

\section{INTRODUCTION}

The system of Theme-Rheme has inestimable value and contribution to the development of texts as a message. Halliday and Matthiessen (2014, p. 64) define Theme as "the point of departure for the message; it is that which locates and orients the clause within its context". Theme is what the clause about, while Rheme is the remainder of the message that develops the Theme. Alyousef (2016) reports that raising students' awareness of thematic development patterns contributes to helping the students to produce a flowing and consistent text.

Theme-Rheme was employed in this paper because the aim is to analyze and assess 7 written texts produced by Saudi engineering students for the purpose of identifying their weaknesses in L2 writing. The focus was on types of Theme, thematic development patterns, and the problems of thematic development. A short proportion of the literature was only reviewed briefly since the present paper is a small-scale one.

\section{Research questions were}

What types of Theme can be found in Saudi engineering students' texts? Which type of Theme is used more? What is the most frequently used thematic progression pattern? What are the problems of thematic progression in the students' texts? This paper aimed to analyze 7 Saudi engineering students' writings for looking at what types of Theme students used to develop their paragraphs thematically, for identifying what patterns of thematic progression were employed. Not only is this but also the researcher aims to bring to the light the problems of thematic development where found in the students' assignments.

\section{Literature review}

An overview of problems of engineering students in L2 writing

Academic writing does involve many different kinds of tasks such as writing assignments and technical reports. In other words, writing a specialized document to specific audience is different from writing a general document (Rus, 2015). Xiao and Chen (2015) and Ibrahim, Yunus and Khairi (2017) undertook a study to identify engineering students' problematic in writing. They reported that the students had three problems: presentation of 
content, structure, and language use. Furthermore, Mahmoud (2017) examined the engineering students' problems in writing at the level of structure and rhetoric. He found that writing in general and writing for producing technical texts represent a problem for the students of engineering. This may in line with what Alsamadani (2017) reported in his study that was to define the needs of the English language for engineering students in Saudi Arabia, where he found writing, in spite of its significance, "still receives less focus in the ESP teaching at higher education" (ibid, 2017, p. 61).

\section{An overview of teaching writing-based SFL}

Systemic Functional Linguistics has been used in various fields of knowledge; however, the focus in this study is on the use of (SFL) for enhancing and improving the competence of writing for learners of English. Aidinlou (2011) carried out an experimental study to investigate the impact of SFL in writing teaching. The researcher selected 60 students majored in TEFL from three Iranian universities. The participants were divided into two groups; one has been taught writing using traditional approach, whereas the second group was taught writing using SFL. The results suggest that students' competence in writing can write better if they are taught about the register which encompasses field, mode, and tenor. Also, exposing students to the different genres according to SFL can help students write texts in regard to context of culture which concentrates on the aspect of culture. Also, Jingxia and Li (2013) undertook an experimental study to examine the quality of writing for Chinese students using thematic structure. There were 50 participants majoring in English; those participants were divided into controlled group and experimental one. The researchers concluded that the system of Theme is of help in terms of elevating the students' ability in writing with cohesion. Moreover, Cahyono (2018) examined the implementation of SFL as an approach in teaching writing. 20 students majored in English participated in the study. Their texts were analyzed qualitatively, in terms of textual meaning and cohesion. The researcher reported that students' competence in writing was developed through SFL. Not only is this but also, they had the competence to be self-editors and to their peers' writing. Also, the use of SFL is of help to teachers to make their students produce coherent texts.

\section{Theme-Rheme in SFL}

Structuring texts cohesively and semantically is based on three components of meaning, namely ideational, interpersonal, and textual. In this present paper, focus will be restricted to textual meanings in terms of thematic progression. The Theme is the point of departure of a message (Halliday and Matthiessen, 2004), while the Rheme is the remainder of the message (ibid). Alyousef (2016) reports that thematic progression has a vital role in text comprehension, and it helps in providing a flow of information in a text; thereby focusing on thematic development in teaching and learning writing is recommended. According to Halliday and Matthiessen (2014), there are three types of theme: topical, interpersonal, and textual. Topical theme can be realized either by participant, circumstance, or process. This type of theme can be a nominal group, a prepositional phrase, or an adverbial group. The topical theme was divided into two subtypes: simple and multiple (Halliday and Matthiessen, 2004). Simple Themes have a topical element, whereas multiple Themes are either interpersonal or textual Themes. Moreover, topical themes can be marked or unmarked. Marked topical theme is found when a clause starts with a circumstance, whereas unmarked topical theme is found when a clause starts with a participant.

Another type is called interpersonal Themes that may be vocative, modal comment adjunct, or (in yes, no interrogative) finite auxiliary verbs. The last type of Theme is initiated with textual Theme which can be realized by conjunction such as and, when, continuatives such as well, yes, or conjunctive adjunct which is initiated by adverbial or prepositional group such as in addition, for instance. In the SFL, the notion of thematic progression lies within the mode of discourse. A successive flow of information in a text contributes to the thematic development (Eggins, 1994). According to Eggins, there are three main patterns of thematic development. These are: Theme re-iteration, zigzag pattern, and multiple Theme pattern (ibid, pp. 302-304). Theme re-iteration contributes to the text cohesion, even though cohesion may not be there. The zigzag pattern is a re-introduction of Rheme that is introduced firstly in the first clause to be then the Theme of the second clause. Below is a figure shows zigzag pattern of thematic development:

\section{Zigzag pattern}

Clause 1

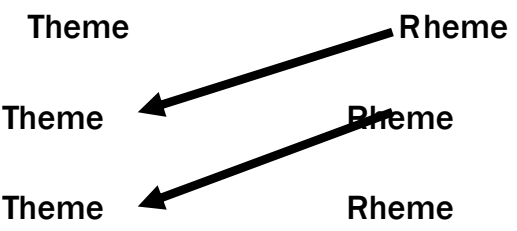

Clause 3

Rheme 
The figure shows that R1 becomes T2 of the second clause. This means that the zigzag pattern creates cohesion within the text by re-constructing of R1 to be presented as new information of the T2. The third pattern of thematic progression is the multiple Theme. Eggins describes the multiple Theme as "Theme of one clause introduces a number of different pieces of information, each of which is then picked up and made Theme is subsequent clauses" (ibid, p. 304). The below figure illustrates the multiple Theme:

\section{Multiple Theme patterns}

Clause 1

Theme

Clause 2

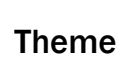

Clause 3

Theme

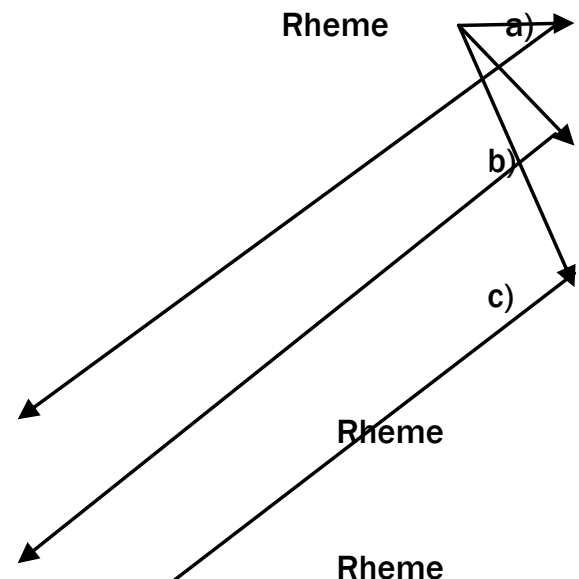

Clause 4

Theme

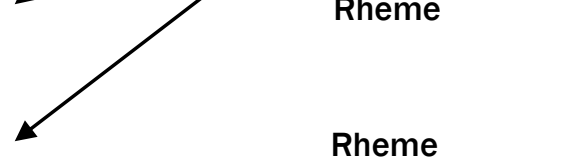

Figure 2 - From Eggins (1994, p.303).

Additionally, identification of what problems of Theme-Rheme, which were committed by the participants, will be located and brought to the light. According to Bloor and Bloor (1992 as cited in Wang, 2007), there are three problems resulted from the misuse of Theme and Rheme, which are: the problem of brand new Theme, the problem of double Rheme, and the problem of empty Rheme. Arunsirot (2013 as cited in Kuswoyo and Susardi, 2017) was also added three problems. These are: the problem of empty Theme, the problem of overuse of constant thematic pattern, and the problem of confusing selection of textual Theme. The problems of Theme-Rheme will be exemplified and explained in the results and discussion section.

Having reviewed some of the literature and to the best knowledge of the researcher, there was not any study examined the engineering Saudi students' problems in writing from the perspective of SFL, in the context of EFL. Therefore, this present paper aims at analyzing short paragraphs submitted by 7 Saudi engineering students as an assignment of a course entitled "Technical Writing Skills". In this paper, I will analyze these texts to identify what types of Theme were used, and to identify what patterns of thematic progression were employed by the students along with locating and bringing to the light the problems of Theme-Rheme.

\section{METHODOLOGY}

Data for this study was collected by 7 Saudi engineering students. The students produced short paragraphs which were a requirement for a course entitled "Technical Writing Skills". They were required to write a short paragraph no less than $\mathbf{1 0 0}$ words related to their field of study to a lay audience. All the participants in the study are from the faculty of engineering. The obtained data was analyzed qualitatively to describe what types of Theme-Rheme were used, and what patterns of thematic progression were employed, and also to identify what problems of ThemeRheme found in the participants' assignments. Analysis of Theme-Rheme was based on the framework of Halliday and Matthiessen's (2014) Theme system. Also, Eggins' book introduction to functional grammar (1994) was used to examine and analyze thematic progression in the students' texts. In addition, Bloor and Bloor (1992 as cited in Wang, 2007) and Arunsirot (2013 as cited in Kuswoyo and Susardi, 2017) were also used to analyze the problems of Theme-Rheme.

\section{RESULTS AND DISCUSSION}

In this section, results of each student's text will be presented and discussed. The analysis of 7 students' texts revealed that the students committed many mistakes in writing a short paragraph. I will present results of the 
analysis for each student along with the discussion of each one to answer the three questions of the current paper. Examples from the students' texts were presented without any amendments.

Examples from student A's text:

Example (a)

\begin{tabular}{|l|l|}
\hline Topical Theme & \multicolumn{1}{|l}{} \\
\hline Marked Theme & Rheme \\
\hline When people hear of architecture engineering, & They think of it as being an architect. \\
\hline
\end{tabular}

Example (b)

\begin{tabular}{|l|l|l|}
\cline { 2 - 3 } \multicolumn{1}{c|}{} & Topical Theme & \multicolumn{1}{c}{} \\
\hline Textual Theme & Marked Theme & Rheme \\
\hline But & These two things & are different from each other. \\
\hline
\end{tabular}

Example (c)

\begin{tabular}{|l|l|}
\hline \multicolumn{1}{|l|}{ Topical Theme } & \multicolumn{1}{|l}{} \\
\hline Unmarked Theme & Rheme \\
\hline An architect & is a person who plans and designs buildings. \\
\hline
\end{tabular}

\section{Example (d)}

\begin{tabular}{|l|l|}
\hline Interpersonal Theme & Rheme \\
\hline You can & think of it this way. \\
\hline
\end{tabular}

The above examples (a, b, c, \& d) show that after analyzing the student's text in terms of types of Theme, the analysis revealed that the student used marked topical Themes, textual Themes, unmarked topical Themes, and interpersonal Theme. Regarding the number of uses, marked topical Themes were used on two occasions, while textual Themes were used on three occasions. The number of unmarked topical Themes outnumbered the previous types of Theme. Also, the analysis found an interesting finding that is that the student used one interpersonal Theme followed immediately by Rheme; this is shown in example (d). Moreover, in relation to the frequently used thematic development and the problems of thematic progression, below are examples followed by an explanation.

\begin{tabular}{|l|l|}
\hline $\begin{array}{l}\text { Theme } \\
\text { Clause 1- When people hear of architecture engineering, }\end{array}$ & $\begin{array}{c}\text { Rheme } \\
\text { they think of it as being an architect. }\end{array}$ \\
$\begin{array}{l}\text { Clause 2- But, these two things } \\
\text { Clause 3- An architect }\end{array}$ & are different from each other. \\
$\begin{array}{l}\text { Clause 4- However, an architectural engineer } \\
\text { engineering. }\end{array}$ & is a person who plans and designs bu ildings.
\end{tabular}

Clauses 3 \& 4 illustrate a multiple Theme pattern. The analysis in terms of thematic progression found that student A employed only multiple Theme pattern which was used on one occasion. There was no use of reiteration pattern. Regarding the problems of thematic development, the analysis uncovered that the student had a problem which is known as the problem of confusing selection of textual Theme. This was found in clause (2), which was the demonstrative pronoun these. Selecting the word these to refer to the previous clause (1) was not appropriate enough. This resulted in unlinked clauses. He should have been used, for example, an existent participant there instead of these or Theme of reiteration pattern. Such a problem takes place when teaching writing is only focused on correct structure rather than both correct structure and coherence to have then unambiguous and connected clauses within a paragraph.

In analyzing student B's text, the analysis revealed that the student utilized different types of Theme. He used unmarked topical Themes, textual Themes, and interpersonal Theme. Instances from the student B's text is provided below. 


\begin{tabular}{|l|l|}
\hline \multicolumn{2}{|l|}{ Topical Theme } \\
\hline Unmarked Theme & Rheme \\
\hline Capacitor & is a tool that works to intensify or assemble something. \\
\hline
\end{tabular}

Example (b)

\begin{tabular}{|l|l|l|}
\cline { 2 - 3 } \multicolumn{1}{l|}{} & \multicolumn{2}{c|}{ Topical Theme } \\
\hline Textual Theme & Unmarked Theme & Rheme \\
\hline In other words & It & $\begin{array}{l}\text { is a device that stores electrical energy in a circuit in the form of } \\
\text { positive and negative charges. }\end{array}$ \\
\hline
\end{tabular}

\section{Example (c)}

\begin{tabular}{|l|l|}
\hline Interpersonal Theme & Rheme \\
\hline It can & $\begin{array}{l}\text { be compared to a small battery (but stores) the energy in an electrical image and releases it in } \\
\text { parts of a second. }\end{array}$ \\
\hline
\end{tabular}

The above examples $(a, b, \&$ c) illustrate that the student employed diverse types of Theme. However, the analysis found that the student mainly and frequently used unmarked topical Themes; there was no use of marked topical Theme. The use of textual Themes was on two occasions, while the use of interpersonal Theme was on one occasion. Furthermore, regarding thematic progression pattern and its problems in the student B's text, examples will be presented followed by explanation.

Theme
is a tool that works to intensify or assemble something.
clause 6- Finally, we
insulating material.
voltage.

The given examples indicate that the analysis revealed that the student B's text was developed using reiteration patterns. The analysis did not find any use of zigzag or multiple Theme patterns. In addition to that, the analysis uncovered mistakes in terms of the use of confusing selection of textual Themes. These were found in clause ( 4 \& 6 ) of the student B's text. Following is an extract from the student's text to clarify the effect of the confusing selection of the textual Themes on the coherence of the paragraph: Capacitor is a tool that works to intensify or assemble something. The capacitor is a device that collects electrical charges. In other words, it is a device that stores electrical energy in a circuit in the form of positive and negative charges. It can be compared to a small battery but stores the energy in an electrical image and releases it in parts of a second. The capacitor consists of the simplest form of two metal plates connected to electricity separated by a thin insulating material. Finally, we use capacitor in electronics or electrical devices to repair a constant currents and (regulating) voltage.

The underlined parts of the extract above illustrate that there was an inappropriate embedded clause due to the use of the textual Theme but. This use was not only resulted in an ill-clause but also it disturbed the flow of Theme and Rheme of the previous and next clauses. Another mistake was found in clause (6) which starts from the word finally. This shows the use of the word finally which was not appropriate since the textual Theme finally is an additive conjunction. This is according to (e.g. Abu Rass, 2015) shows one difficulty that Arab students in general face in their writing. In analyzing student C's text, the analysis found that the student utilized two types of Theme, namely topical Themes and textual Theme. Examples are provided below along with the illustration. 


\begin{tabular}{|l|l|}
\hline Topical Theme & \multicolumn{1}{|l}{} \\
\hline Unmarked Theme & Rheme \\
\hline The generator & $\begin{array}{l}\text { is a device that converts the mechanical power into electrical power } \\
\text { for use in an external circuit. }\end{array}$ \\
\hline
\end{tabular}

\section{Example (b)}

\begin{tabular}{|l|l|l|}
\cline { 2 - 3 } \multicolumn{1}{l|}{} & Topical Theme & \multicolumn{1}{c}{} \\
\hline Textual Theme & Unmarked Theme & Rheme \\
\hline The first & $\begin{array}{l}\text { Electromagnetic generator, the } \\
\text { Faraday disk }\end{array}$ & $\begin{array}{l}\text { was invented in 1831 by British scientist } \\
\text { Michael Faraday. }\end{array}$ \\
\hline
\end{tabular}

\section{Example (c)}

\begin{tabular}{|l|l|}
\hline Topical Theme & \\
\hline Marked Theme & Rheme \\
\hline Despite their differences, & $\begin{array}{l}\text { all these generators should undergo similar generator maintenance to ensure } \\
\text { long-term. }\end{array}$ \\
\hline
\end{tabular}

Above examples $(a, b, \& c)$ are to exemplify the types of Theme found in the student C's text. In relation to the frequent use of these types, the analysis revealed that the number of using unmarked topical Themes was on seven occasions, whereas marked topical Theme was used on one occasion. Second type of Theme is the textual Theme that was used on one occasion. In relation to interpersonal Themes, the student did not use any interpersonal Themes. Additionally, the analysis of thematic progression patterns and the problems of Theme-Rheme development revealed the following results. Examples from the student C's text are provided along with the elaboration.

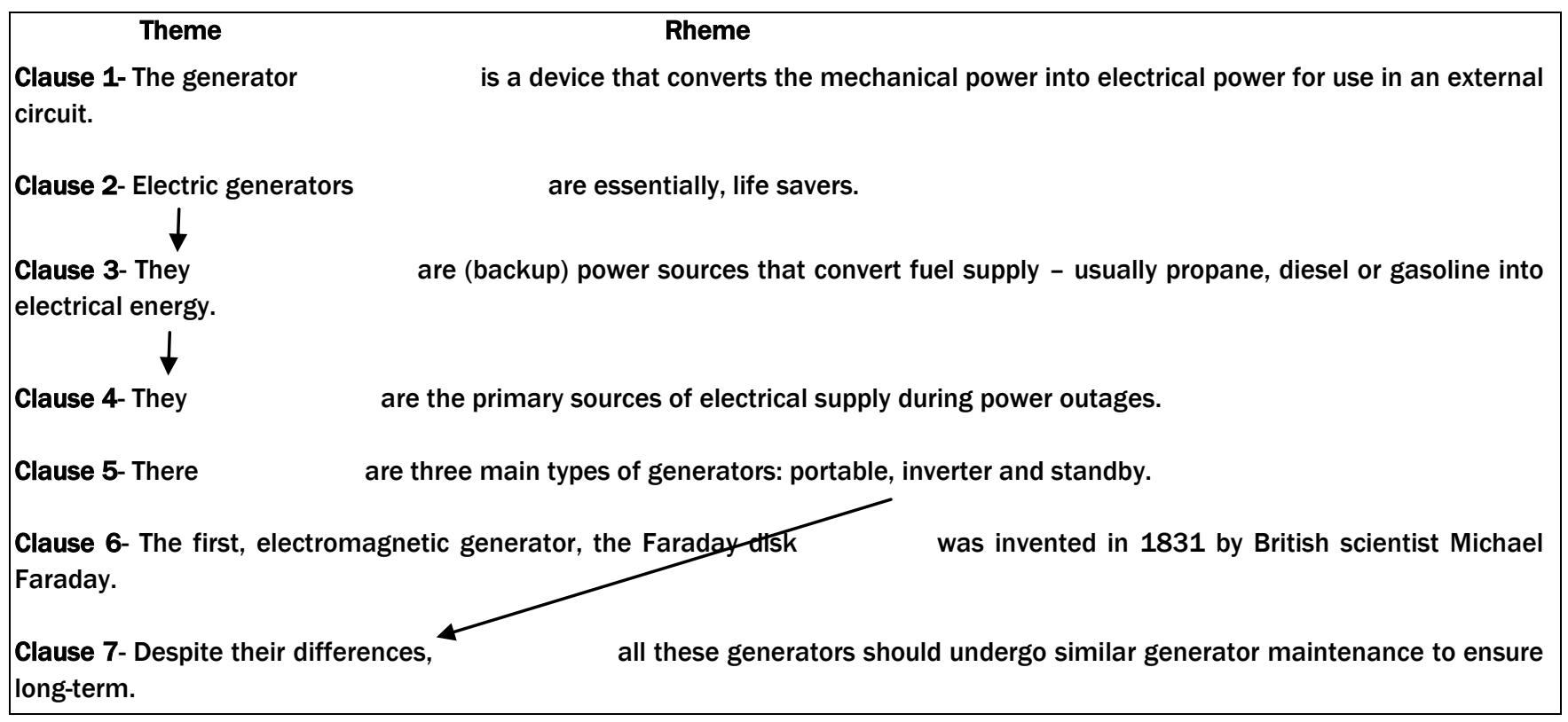

In regard to the thematic progression patterns, the analysis revealed that the use of reiteration patterns was found on two occasions; these are shown in clauses (2-4). There was one use of zigzag pattern; this is shown in clauses (5-7). There was no use of multiple Theme pattern. Also, the analysis uncovered that the student had a problem in developing his Theme. This problem, according to Bloor \& Bloor as cited in (Wang, 2007), is known as the problem of brand new Theme. This problem is defined as that it is to put new information in the Theme position. This information is not connected to the previous Theme or Rheme. From the examples above, the problems were found in clauses (1 and 6); the student did not develop his Theme into next clauses; he just introduced brand new Themes. This resulted in creating an inconsistent paragraph. Analyzing student D's text uncovered the following findings:

Example (a) 


\begin{tabular}{|l|l|}
\hline \multicolumn{1}{|l|}{ Topical Theme } & \multicolumn{1}{|c}{} \\
\hline Unmarked Theme & Rheme \\
\hline Electrical current & is the blood of any electrical circuit. \\
\hline
\end{tabular}

\section{Example (b)}

\begin{tabular}{|c|c|c|}
\hline 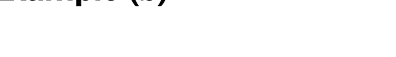 & Topical Theme & \\
\hline Textual Theme & Unmarked Theme & Rheme \\
\hline To make it less imagination, & Electrical current & is exact \\
\hline
\end{tabular}

The student used mainly unmarked topical Themes, while the use of textual Theme was on one occasion. There was no use of interpersonal Theme. Also, the analysis revealed many mistakes committed by the student in relation to Theme-Rheme development. Instances are given below followed by the explanation.

\begin{tabular}{|c|c|}
\hline $\begin{array}{c}\text { Theme } \\
\text { Clause 1- Electrical current }\end{array}$ & $\begin{array}{l}\text { Rheme } \\
\text { od of any electrical circuit. }\end{array}$ \\
\hline Clause 2- A human without blood & human. \\
\hline Clause 3- An electrical circuit without current & is an inactive circuit. \\
\hline Clause 4- Everything related to any electricity & ted to the electrical current. \\
\hline Clause 5- To make it less imagination, electrical current & is exactly like the water flow. \\
\hline
\end{tabular}

Clauses (1-3) show problems of Theme-Rheme development, while clauses 4-6 show the use of zigzag pattern, which occurred on two occasions. The analysis did not find any use of reiteration or multiple Theme patterns. Moreover, the analysis found that the student had a problem in developing his Theme. This can be seen in clauses $(1,2, \& 3)$ where the student introduced brand new Themes which were not either developed through thematic progression patterns or connected using textual Themes, so these clauses interrupted and affected the whole paragraph. This participant failed in producing his text consistently.

In addition to the given results, student E's text was also analyzed. Following are examples and discussions of the findings.

\section{Example (a)}

\begin{tabular}{|l|l|}
\hline Topical Theme & \multicolumn{1}{|l}{} \\
\hline Unmarked Theme & Rheme \\
\hline Concrete & $\begin{array}{l}\text { is a composite material composed of fine and coarse aggregate (bonded) together with fluid } \\
\text { cement that harden over time. }\end{array}$ \\
\hline
\end{tabular}

\section{Example (b)}

\begin{tabular}{|l|l|}
\hline Topical Theme & \multicolumn{2}{|l}{} \\
\hline Marked Theme & Rheme \\
\hline If the concrete has only fine aggregate in it, & we call it mortar. \\
\hline
\end{tabular}

\section{Example (c)}

\begin{tabular}{|l|l|l|}
\cline { 2 - 3 } \multicolumn{1}{c|}{} & Topical Theme & \multicolumn{1}{c}{} \\
\hline Textual Theme & Unmarked Theme & Rheme \\
\hline And & coarse aggregate & is rocks. \\
\hline
\end{tabular}

Above examples, (a-c), are from student E's text. It indicates that almost all the text was built up of unmarked topical Themes. There was only one use of marked topical Theme, while the use of textual Themes was found on two occasions. The analysis did not find any use of interpersonal Theme. In relation to the thematic progression patterns and the problems of developing Theme-Rheme in student E's text, they are exemplified and discussed below.

Theme Rheme




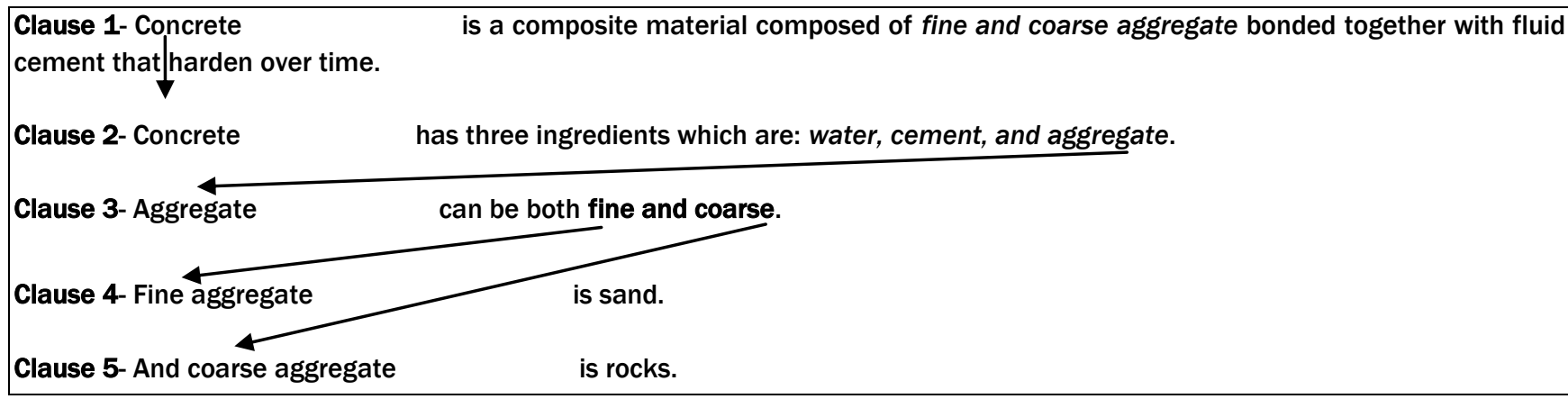

The analysis revealed that student E's text was developed mainly using three thematic progression patterns. Reiteration patterns followed by zigzag patterns and multiple Theme patterns were all used. Reiteration patterns were used on three occasions; one example provided above. Zigzag patterns were used on two occasions, and one example is given above, while multiple Theme patterns were utilized on one occasion.

Even though the student developed his text using the three thematic progression patterns, the analysis found some problems in terms of Theme-Rheme development. First, the student did not develop the Rheme of the first clause; he just repeated himself. In clause (1) above, there is a problem of empty Rheme which means the participant put the Rheme that was not developed in the second clause. In other words, the participant should have been focused on the components of concrete instead of repeating himself, even though clause (2) seems good to be the introductory departure point to the paragraph. Because of this, the first clause was with no link to the next one in terms of the organization of the paragraph. This cause led to creating unorganized text.

Analysis of participant F's text uncovered that the student used mainly unmarked topical Themes in building his text. There was one use of marked topical Theme and interpersonal Theme. The analysis did not reveal any employment of textual Themes. Examples are shown below:

\section{Example (a)}

\begin{tabular}{|l|l|}
\hline \multicolumn{1}{|l|}{ Topical Theme } & \multicolumn{1}{|l}{} \\
\hline Unmarked Theme & Rheme \\
\hline Diode & is an electric circuit element that is used widely around the world. \\
\hline
\end{tabular}

\section{Example (b)}

\begin{tabular}{|l|l|}
\hline Topical Theme & \multicolumn{1}{|l}{} \\
\hline Marked Theme & Rheme \\
\hline When voltage gets over a certain level, & it breaks down and allows the current to move. \\
\hline
\end{tabular}

\section{Example (c)}

\begin{tabular}{|l|l|}
\hline Interpersonal Theme & Rheme \\
\hline You can & imagine it like the window glass in the day. \\
\hline
\end{tabular}

Regarding the thematic progression patterns and the problems of developing Theme-Rheme, the analysis revealed the following results followed by elaboration:

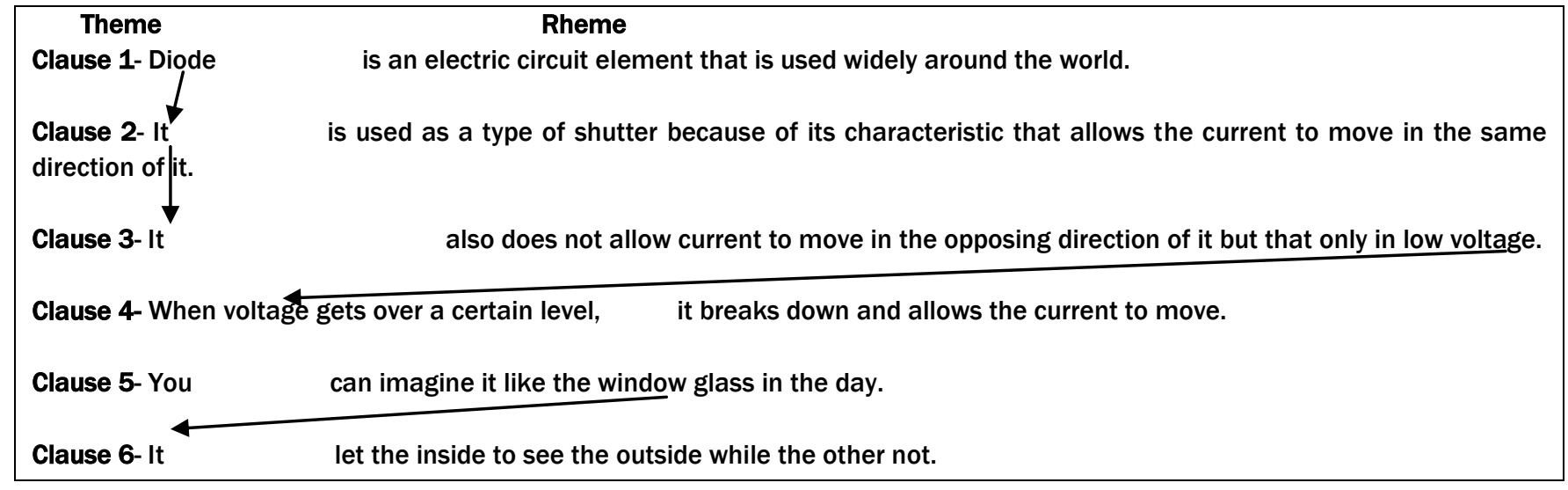


The analysis revealed that the student used reiteration patterns on two occasions; also, zigzag patterns were utilized on two occasions. There was no use of multiple Theme patterns. In the third clause, the analysis revealed that the student did use a wrong textual Theme also. This is known as the problem of confusing selection of textual Theme. Last but not least, student G's text was analyzed; the analysis revealed that mainly the student used unmarked topical Themes in his text. There was only one use of textual Themes. Interpersonal Themes were not used. Examples are provided below:

\section{Example (a)}

\begin{tabular}{|l|l|}
\hline Topical Theme & \multicolumn{1}{|l}{} \\
\hline Unmarked Theme & Rheme \\
\hline Resistor & $\begin{array}{l}\text { is an electrical component that limits or regulates the flow of the electrical current in an electronic } \\
\text { circuit. }\end{array}$ \\
\hline
\end{tabular}

\section{Example (b)}

\begin{tabular}{|l|l|}
\hline Textual Theme & Rheme \\
\hline These & are used to reduce current flow and voltage level in an electric circuit, among other uses. \\
\hline
\end{tabular}

In response to the second and third question of the paper, the analysis of thematic progression patterns also uncovered that the student G's text was well developed. Examples and elaborations are below:

\begin{tabular}{|c|c|}
\hline $\begin{array}{l}\text { Theme } \\
\text { Clause 1- Resistor } \\
\text { circuit. }\end{array}$ & $\begin{array}{l}\text { Rheme } \\
\text { is an electrical component that limits or regulates the flow of the electrical current in an electronic }\end{array}$ \\
\hline $\begin{array}{c}\text { Clause 2- The resistors } \\
\qquad\end{array}$ & are among the passive component family in the electrical circuit. \\
\hline Clause 3- These & are used to reduce current flow and voltage level in an electric circuit, among other uses. \\
\hline Clause 4- There & are many types of resistors such as Fixed resistors and variable resistors. \\
\hline Clause 5- Fixed Resistors & have resistances that only changestisttty with temperature, time or the applied voltage. \\
\hline Clause 6- Variable resistor & can be used to adjust circuit elements, for example, volume control, a lamp dimmer, as sensing \\
\hline
\end{tabular}

The analysis above shows that the student used reiteration Theme on two occasions, whereas multiple Theme patterns were employed on one occasion. There was no use of zigzag patterns. What can be revealed also through the analysis is that the student to some extent could develop his text, even though he is not conversant with the notion of Theme-Rheme system.

\section{CONCLUSION}

In conclusion, this current paper was carried out for the purpose of identifying the problems of Saudi engineering students in writing. The paper focuses mainly on analyzing the students' texts in terms of types of Theme, the most frequently used thematic progression patterns, and the problems of thematic progression in the students' texts. Results indicate that all the students mainly used unmarked topical Themes. Also, four students utilized marked topical Themes with differences in terms of the number of uses. Moreover, six students used textual Themes in their writings, while three students employed interpersonal Themes in their texts.

In relation to the thematic progression patterns and the problems committed by the students, the results came up with that all the students used reiteration patterns and zigzag patterns, whereas three students used multiple Theme patterns. Furthermore, six participants encountered problems in developing their paragraphs. These problems were: the problem of brand new Theme, the problem of confusing selection of textual Themes, the problem of empty Rheme, and the problem of using cohesive devices inappropriately.

This paper does not only aim at analyzing and discussing those participants' texts but also disseminating the significance of the notion of Theme-Rheme system in the context of Saudi Arabia. The paper suggests that the EFL/ESL students must be taught explicitly how to develop their writing by employing thematic patterns and how to 
avoid committing the problems of thematic development in order to be aware of their writing and to have the competence in revising their texts with confidence.

\section{Further investigation}

The data of the present paper was not enough to recommend pedagogical implications; therefore, other studies with large data are needed to investigate deeply the difficulties that Saudi students majoring in engineering face when writing in L2. Not only is this but also exposing EFL students to a new resource of the language, namely SFL may help in changing the students' view about writing skill.

Counting the problems of thematic progression in Saudi engineering students' writing will help in assisting them to be aware of thematic patterns and to keep the notion of Theme-Rheme in their consideration when writing. This will also enable us to be in a position to determine what the most frequently thematic progression problems students may face in their writing in order to recommend pedagogical implications that can be of benefits to the students of engineering faculty.

\section{DECLARATION}

\section{Acknowledgement}

I would like to thank Prof. Hesham Alyousef for his valuable comments and revision.

\section{REFERENCES}

Abu Rass, R. (2015). Challenges face Arab in writing well-developed paragraphs in English, English Language Teaching, Vol. 8, No. 10, pp. 49-59. DOI: 10.5539/elt.v8n10p49

Aidinlou, N. A. (2011). A discourse-based teaching of writing for Iranian EFL students: A systemic perspective, Journal of English Language Teaching and Learning, Vol. 3, No. 8, pp. 53-70. https://elt.tabrizu.ac.ir/issue_150_152.html

Alsamadani, H. A. (2017). Needs analysis in ESP context: Saudi engineering students as a case study, Advances in Language and Literary Studies, Vol. 8, No. 6, pp. 58-68. DOI: http://dx.doi.org/10.7575/aiac.alls.v.8n.6p.58

Alyousef, H. S. (2016). A multimodal discourse analysis of the textual and logical relations in marketing texts written by international undergraduate students, Functional Linguistics, a Springer Open Journal, Vol. 3, No. 3, pp. 1-29. https://doi.org/10.1186/s40554-016-0025-1

Cahyono, S. P. (2018). Teaching L2 writing through the use of systemic functional linguistics (SFL), Indonesian Journal of English Language Teaching, Vol. 13. No. 1, pp. 53-72. http://dx.doi.org/10.25170\%2Fijelt.v13i1.1179

Eggins, S (1994). An introduction to systemic functional linguistics, St. Martin`s press: Pinter publishers Ltd: London.

Halliday, M.A.K; \& Matthiessen, M.I.M, (2004). An introduction to functional grammar (3rd ed.), Arnold: UK.

Halliday, M.A.K., and Matthiessen, M.I.M. (2014). An introduction to functional grammar. $3^{\text {rd }}$ edition, Arnold: UK.

Ibrahim, S., Yunus, M. A. M., and Khairi, M. T. M. (2017). Teaching academic writing for engineering students: Challenges and recommendations, International Journal of Education, Psychology and Counseling, Vol. 2, No. 5, pp. 160-169. http://www.ijepc.com/archived.asm

Jingxia, L and Li, L. (2013) An empirical study on the application of Theme theory in the field of writing pedagogy, English Language Teaching, Vol. 6, No. 5, pp. 117-128. D0l:10.5539/elt.v6n5p117

Kuswoyo, H. and Susardi. (2017). Problems on SFG thematic progression in ESL academic writing, Leksema, Vol. 2, No. 1, pp. 113. DOI : $10.22515 /$ libs.v2i1.655

Mahmoud, S. S. (2017) Investigating the English language structural and rhetorical needs of engineering students at King AbdulAziz University, Journal of Education and Training, Vol. 4, No. 1, pp. 55-68. https://doi.org/10.5296/jet.v4i1

Rus, D. (2015). Developing technical writing skills to engineering students, $8^{\text {th }}$ international conference interdisciplinary in Engineering, INTER-ENG 2014, 9-10 October 2014, Tirgu-Mures, Romania, Procedia Technology 19, pp. 1109-1114. https://doi.org/10.1016/j.protcy.2015.02.158

Wang, L. (2007). Theme and Rheme in the Thematic Organization of Text: Implications for Teaching Academic Writing, Asian EFL Journal, Vol. 9, No. 1, pp. 164-176. https://www.asian-efl-journal.com/main-editions-new/theme-and-rheme-in-thethematic-organization-of-text-implications-for-teaching-academic-writing/

Xiao, G. and Chen, X. (2015). English academic writing difficulties of engineering students at the tertiary level in China, World Transactions on Engineering and Technology Education, Vol. 13, No. 3, pp. $259-263$. http://www.wiete.com.au/journals/WTE\&TE/Pages/TOC_V13N3.html 